\title{
EAMR
}

European Accounting and

Management Review

EUROPEAN ACCOUNTING AND MANAGEMENT REVIEW · VOL.2, NO.1, 104-122 NOVEMBER 2015

\section{Justice: a sufficient condition for goal congruence in management control systems}

\author{
Natàlia Cugueró-Escofet \\ IESE Business School \\ Josep M. Rosanas \\ IESE Business School
}

Received October 9, 2015; accepted October 19, 2015.

\begin{abstract}
Control systems are a fundamental tool in the management process. Management control systems have been judged under the criterion of goal congruence, i.e., on whether the possible rewards given to people when they take specific actions benefit at the same time individuals and the organization as a whole. Often the concept of justice is not included in the analysis. In recent papers, some theoretical developments have shown that the concept of justice is essential to their dynamics, because it has the potential to change the attitudes of people towards the organization and, therefore, their interest in future decisions. But these developments have been essentially conceptual and have not attempted to go beyond theoretical terms. This paper, using a stylized example, tries to show how this framework can be applied in practice. It also attempts to clarify the concept of goal congruence, by distinguishing when it is merely quantitative or qualitative, and when it can be considered ' weak ' or ' strong '. Finally, it goes back to the conceptual model of Cugueró-Escofet and Rosanas (2013) and shows how the practical vision of this case adapts to the conceptual analysis offered in their framework, and draws some conclusions.
\end{abstract}

\section{KEYWORDS}

Management control systems, goal congruence, formal justice, informal control systems, informal justice. 


\section{Introduction}

The conventional theory of management control systems, primarily the one that focuses on performance evaluation of specific people and organizational units through a set of indices, has classically developed around the concept of goal congruence. The ideal of goal congruence is the property of a system where the evaluation and rewards are such that when people act to pursue their own interest, they are at the same time acting in the best interest of the organization. Although we will analyze the concept in more detail below, starting with the intuitive ideas we may say that when referring mainly to quantitative indices and results, the usual textbook conclusion is that, at the end, in most situations, a perfect alignment does not exist. Performance indices or indicators are in this context often called "metrics", just to give the impression that they consist of precise measures that enjoy nice mathematical properties. Unfortunately, they do not, so this very popular name is actually a misnomer; and as we will see, qualitative variables have to be taken into consideration for a good solution to exist.

However, when management control systems was just starting, back in the 60's of last Century, some scholars (mainly Richard Vancil, of the Harvard Business School) already considered that it was crucial that quantitative goal congruence should be complemented with the criterion of fairness, which might even be the first priority criterion (Vancil 1973). Fairness, from a practical point of view, was at that time taken to mean the classical concept of controllability: people and organizational units should be evaluated with indicators that reflect variables over which they can exert some control, and therefore are not the result of chance, of what others do, or of general economic conditions. In the $80 \mathrm{~s}$, another Harvard professor made fairness the focal point of transfer pricing, one of the thorniest issues in the management control area (Eccles 1983, 1985).

Fairness and justice are quite obviously related, and sometimes used interchangeably, even if some recent literature has tried to conceptually distinguish between the two (Cropanzano and Goldman 2014, Cugueró-Escofet and Fortin 2013). The word justice has seldom appeared in the accounting literature, except lately in conceptual studies of a rather abstract character. In two recent papers, for instance, Cugueró-Escofet and Rosanas $(2013,2015)$ attempt to study justice in control systems thoroughly, by establishing the distinction between informal and formal justice and incorporating both as the key elements that must be part of the design and the use of management control systems in order to achieve maximum levels of goal congruence. Theirs, therefore, is an approach 
that links justice with the possibility that the goals of the company and the goals of its executives are aligned to some degree.

Nevertheless, these studies, like some others, have not dealt with the practical issue of how justice can be introduced specifically, and this is by no means a trivial task. There is empirical evidence that certain aspects of justice perceptions relate to management control systems (see for instance Coletti et al. 2005, Hartmann and Slapnicar 2009), but these studies are not based on a conceptual analysis of justice in the context of management control systems. Also regarding practical implications of implementing justice in management control systems there is little evidence regarding core constructs (i.e. goal congruence), except from some studies that link some management control system characteristics to the reduction of unethical behaviors through the improvement of fairness perceptions of these systems (Langevin and Mendoza 2013). Therefore, the application of the framework suggested may become quite difficult. The aim we pursue in this paper is precisely to initiate the study of how a conceptual framework of justice can be applied in business practice. We therefore ask how this conceptual framework, that has been theoretically developed, can be put into practice, i.e., how do we go from rigorously derived concepts of justice to accounting numbers and performance evaluation practice. In order to do this, we will base our arguments on a case study that represents a prototypical situation that is fairly common in many companies (mainly multinationals), so that it can be seen to be realistic and easily applicable. Thus, we do not attempt to generalize from our case (which, incidentally, as stated below, is a composite of real world cases), but just to explore how the abstract ideas developed by Cugueró-Escofet and Rosanas $(2013,2015)$ can be put into practice in specific situation.

We will proceed as follows: we will first elaborate on the concept of goal congruence, explaining the types of goal congruence and the relative importance they could have in terms of aligning in the long term managerial decisions with organizational objectives. Second, we present a specific case where a situation of justice and goal congruence exists. Finally, we conceptually develop the idea that informal justice is sufficient to achieve a sustainable level of goal congruence that could reach a maximum level and include qualitative aspects. 


\section{Goal congruence and its possible types}

As mentioned before, the concept of goal congruence has historically been considered a central concept of management control systems theory. Anthony, in one of the key books of the area, defined management control as the process by which "managers influence other members of the organization to implement organizational strategies" (Anthony 1988, p.10). In order to do that, this influence should occur in a way that when managers pursue their own self-interest, they will do it in a way that they take at the same time those actions that are the best for the organization as a whole. This property of the system is what Anthony called goal congruence.

However, goal congruence is not a static property of the formal system that remains constant. On the contrary, it may change through time with several possible factors: the general economic circumstances, the evolution of the industry and the competitors, the internal strategy and structure of the firm, and the attitudes of employees towards the organization, just to name a few. Actually, many of these factors originate in the fact that all agents, whether they want it or not, learn through time, and therefore change their decision rules and their behavior in general.

In any interaction between two people (boss and subordinate, customer and supplier, stockholder and administrator, to just mention a few of them), the two of them typically want to obtain a specific external result (sales, profit, a new facility, a new organizational structure, etc.). Nevertheless, inevitably they will modify their information, their beliefs, their skills and their attitudes as the result of the interaction. That is what we mean by learning. Thus, learning is not limited to the accumulation of knowledge or increasing one's ability to perform certain tasks. It includes these conventional, well-known forms of learning, as well as implicit learning, non-transferable knowledge embedded into the agents that take part in the actions, and even changes in their attitudes towards each other (Polanyi 1974, Rosanas 2008, 2013).

The justice associated with the structure of the control system and its use heavily influences these last types of unconventional learning. Whether employees feel they are being treated justly or unjustly by the organization is a crucial element in their future attitudes towards that organization: if management is unjust in decision-making, this is likely going to produce adverse reactions that may seriously affect negatively the company in the future.

However, this is not the only reason why justice is important: justice is a virtue, and so, since ancient philosophy, most people consider that "being just" is what they should do. 
Aristotle already said that there is learning from this point of view too: when a person acts justly, becomes just; and when acting unjustly, becomes unjust (Aristotle 2000, Book V). Socrates considers that being just is concerned with happiness whether being unjust with the opposite state of the soul (Plato 2006, Book I). In our context, a substantial part of actions that are just or unjust within an organization has to do with its management control system: both the goals set through the system and the evaluation and rewards that stem from them are crucial in people's perception of justice (Langevin and Mendoza 2013).

Goal congruence plays an important role in this context, and it is important to distinguish between different versions of it. First, goal congruence can be considered to take into account quantitative variables only, or to include qualitative variables as well. CugueróEscofet and Rosanas use a concept that includes mainly the latter; but often goal congruence is analyzed with respect to the quantitative variables, even to the exclusion of the others. For instance, the typical textbook treatment of this issue is somewhat paradoxical: on the one hand, they often devote a chapter to motives other than the purely financial ones; but on the other, the analysis in the rest of the chapters is essentially based on the financial variables. Then, the goal congruence is purely quantitative. This is what happens in the typical situation between the company and one of its divisions: the textbook analysis consists in ascertaining whether the company's profit (or contribution margin, or any other alternative financial variable) goes in the same direction as the similar variable of the division (see, for instance Anthony and Govindarajan 2003, Merchant and Van der Stede 2007, Simons 1999). If it is, this is considered enough of a reason to tie the monetary incentives of the people in charge of the division to the corresponding divisional financial variable. Obviously, simplifying the whole problem to its quantitative, financial dimensions is a serious reductionism: people's motives are much broader, as the chapter on the subject of all these books rightly state, even if this is not further developed later on.

Nonetheless, even if for some purposes we take only the quantitative variables into consideration, there is an aspect that is often forgotten: it may not only be a matter of the divisional and the firm-wide variable pointing towards the same direction: the two variables may have substantially different values, perhaps even different orders of magnitude. Suppose, for instance, that a division of a firm is a profit center (and, thus, is evaluated on its gross profit), and the same is true for the firm as a whole. Further assume that the firm has a transfer pricing system by which Division A, which is working below 
capacity sells Product X to Division B at a transfer price which equals its variable cost plus $5 \%$. Division B, which is also working below capacity, processes the product further and sells it with a contribution of $40 \%$ the selling price. The cost to Division B of Product $\mathrm{X}$ is $21 \%$ of the selling price; thus, the total contribution to the firm is $41 \%$ of the selling price. Then, there is quantitative goal congruence between each one of the divisions and the company as a whole: in both cases, accepting a new order will result in an increase of profits both for the divisions and for the company as a whole. But the magnitude is quite different: the contribution for Division A is only $1 \%$ of the selling price, the contribution to Division B is $40 \%$, and the contribution for the firm as a whole is $41 \%$. Whenever this happens, it may look a little bit unfair from the beginning, but we must hasten to add that whether it actually is unfair or not depends on many circumstances (for instance, the real contribution to the sales volume of each division). In any case, the quantitative goal congruence between the firm and Division B is of a similar magnitude, while that between the firm and Division A is 41 times bigger. We will then say that there is weak goal congruence between Division A and the firm as a whole, and strong goal congruence between Division B and the firm.

In theory, a profit maximizer would make the same decisions no matter whether goal congruence is weak or strong (or, in practical terms, the same for a cent than for $100 €$ ) but we know that in practice this is not true. Therefore, if we take into account qualitative variables, it may happen that a situation that was originally goal congruent may become goal incongruent. If, at some point in time, because of any reason, it turns out that manufacturing an order of Product X requires a lot of 'effort' from Division A, Division A may decide not to do it, thereby originating a big opportunity loss to the firm as a whole. Qualitative aspects are therefore crucial to understand managerial motivations, and to influence people to take one or other decision.

This would not happen with Division B except under very exceptional circumstances. If Division B decides not to manufacture the final product because of other qualitative variables are very important and the $40 \%$ contribution is not enough to compensate for them, it is very likely that the same argument can be applied to the firm as a whole, making then the decision optimal.

Obviously, we can reason similarly with quantitative goal incongruence. Suppose now a different situation where the decision to be made is goal incongruent between the firm as a whole and Division A, but the incongruence is weak. Division A may be willing to make the effort to say 'yes' for the sake of the company as a whole, even though its profits will 
decrease: the loss is not so important. Division A may think, though, that the system is unjust; but precisely, this is what we want to examine in more depth in this paper. A manager may decide against his short-term interests because the company will earn a lot, and believes the boss above will recognize his effort, and that this effort would pay in terms of recognition, and expecting that in the long-term these types of situations will even out. However, if the loss of the division is large, the manager may not want to accept and simply 'adapt' to the rewards implied by the formal control system, thus making the wrong decision for the firm as a whole. Such a manager would have an excellent excuse: he simply adapts to the formal control system of the firm. Nobody can deny that. However, it is obvious that the consequences are not that good now, and in the long-term they may become worse.

So in summary, we distinguish between purely quantitative goal (in)congruence that affects only quantitative variables, and qualitative goal (in)congruence in case it also incorporates qualitative aspects. Quantitative goal congruence may then be weak or strong depending on the relative magnitude of the gains or losses each party makes.

The purpose of this article, as we stated earlier, and now we can reaffirm, is to show how the notion of (mainly informal) justice and its application in the management control process, can solve problems that normally mere quantitative goal congruence cannot solve, mainly if it is weak. In fact, informal justice is indispensable in any context where qualitative variables are important. We also stated that at an abstract level of analysis, this problem has been studied in some depth, even if different types of goal congruence were not distinguished, and more over these analyses do not include how to apply this in practice. We will now see in the context of a specific case how the distinction between formal and informal justice is crucial for that purpose. We will do this by illustrating our arguments in the context of a case that actually is a combination of real-world cases, although we have simplified them to some extent.

\section{Case Blogisar}

The company Blogisar is a large company with several divisions each of which produces and sells specific products, mainly chemicals. One of them is exclusively produced in a plant originally established in Germany, while selling it throughout the whole Western Europe. The plant was considered a profit center, i.e., its managers were evaluated according to the profits obtained. This practice was working smoothly and without special 
trouble, beyond the usual problems that a profit center can have, since it did not compete with any other division.

In 1998, the market of Eastern Europe promised to be important for its product, and as the Southern market grew as well, the company decided to increase capacity. Top management then made the decision to renew the main factory in Germany, and build a new plant in Tarragona to manufacture and sell this product. The facilities that were installed in Tarragona were the original German ones, which were in very good condition. The new German plant was of a much greater capacity in order to accommodate for the expected future growth in demand, even if the initial capacity installed greatly exceeded the estimated short-term demand. The company expected that in the coming years demand would increase and this would justify the additional capacity investment.

The installed production facilities in Tarragona would serve to supply the market in Southern Europe. Since the product was not differentiated, the variables that determined profitability were essentially managing sales, costs, and capacity management. Already planned from the beginning, the plant in Tarragona worked virtually at a full capacity; and for that reason in case of needing more product, it would be possible to import product from the German Division that as mentioned, initially was manufacturing with an excess capacity.

The Tarragona division had from the beginning a demand higher than that originally expected, and in only a few months, they were working at capacity and had to import some amount of product from Germany. They thought it was conceivable that in some specific orders Germany might use product manufactured in Tarragona, but if this happened it would be only in small amounts and for brief periods of time.

The cost system of the German division allocated fixed costs to the product units based on the total capacity of the plant, as it is customary in many activity-based cost systems. The immediate accounting consequence was that from the beginning a volume variance was budgeted (the cost of unused capacity), that was unfavorable and already included in the budget, which of course it affected the income of the German division, and therefore the whole company.

From the beginning, the company decided that if the German division was evaluated on divisional profits, for the division in Tarragona they should do the same. When transfers started from Germany to Tarragona, they decided they would be valued at standard total cost, with a full allocation of fixed costs in Germany. The top management team of the 
company believed that this was 'fair' and eliminated the need for a transfer pricing system.

Nevertheless, it was not long after Tarragona started its operations that some problems begun to appear. The budget of the German Division included a 'budgeted volume variance', because they knew that, for a number of years, they would not be able to be at full capacity and did not want to 'blame' the tons actually produced for the fixed costs of the plant. This budgeted volume variance, of course, was calculated taking into account the expected demand from Tarragona. The problem arose when Tarragona actually ordered from Germany less units that it had budgeted. Then, Germany had an actual volume variance that was higher than expected because of decisions made in Tarragona. It then seemed that something was wrong with the system: it was pushing Tarragona to do something that is 'bad' for Germany.

Tarragona preferred to produce internally as much as possible, because of two obvious reasons. First, the variable costs in Tarragona were less than the variable costs in Germany. And second, it did not have to pay for the fixed costs that the German division charged for each ton. Tarragona already worked at full capacity; so, its fixed costs were already absorbed at their level of production and current sales. Indeed, it had a favorable volume variance. Tarragona had been particularly good at increasing actual capacity, through better production scheduling, efficient maintenance and improvement of their own methods. Therefore, even though they had planned to order a number of tons from Germany, the actual number was less, because they had 'squeezed in' some additional production in their plant. The consequence was an unexpected volume variance and an accounting loss for the German Division.

Let us be more specific and look at some of the main numbers. The total fixed costs in Germany were 70.000.000 euros and estimated capacity was 100,000 tons so the fixed cost per ton was about 700 euros. The total fixed costs in Tarragona were 31,000,000 euros and estimated capacity was 50,000 tons, so the fixed cost per ton was 620 euros. In Germany the variable cost was 410 euros per ton and in Tarragona was 390 euros, so the difference is small but significant. Both fixed costs and variable costs of Tarragona were lower than those of Germany due to the lower cost of labor, to the fact that raw materials for the Spanish market had a lower price and finally because of the high costs of land and facilities in Germany.

So, with these figures let us next examine what the right decisions should be and to what extent the system is goal congruent. 


\section{The quantitative objectives of Blogsiar and its divisions}

Let us first examine the objectives of Blogisar as a whole. We will restrict ourselves to the main quantitative variables, because including other qualitative variables would require a much deeper analysis for which we have no space. Then, from this point of view, what Blogisar wanted was profit, growth and profitability with a good quality product.

The decision to expand capacity in Germany and to build a plant in Tarragona has to be seen in this context. Then, taking these general objectives as given, we can easily derive the objectives that the two divisions should try to accomplish. The objective of Tarragona should be to sell as much as possible, importing from Germany if necessary, and to produce as efficiently as possible, keeping costs controlled and preserving quality. In contrast, the German division objectives had to put more emphasis in increasing sales, because real profitability had to be based on full utilization of capacity as soon as possible in the future. This would be done, obviously, with efficient operations and by keeping costs as low as possible as well.

\section{The current formal control system: profit enters}

At the origin of the problem was the decision to make the two divisions profit centers. It is often argued that profit centers in independent divisions favors decentralization, because if every division acts as an independent firm, the profit of that division will be the same as the profit the division adds to the company as a whole, therefore producing strong quantitative goal congruence. The main problem with profit centers is of course the possible existence of interdependence between the divisions, mainly what was called by Thompson (1967) 'sequential interdependence', which calls for transfer pricing. Sometimes, naïvely, some companies try to avoid the problem by transferring products 'at cost', but cost (variable or full, and with or without a mark-up) is simply an implicit transfer price, in the sense that it determines what part of the profit goes to every division. As we will see, this is a crucial problem at Blogisar.

Quantitatively, the problem is rather simple. As stated above, Tarragona prefers to manufacture itself if possible, because if it imports from Germany, the 'transfer price' is the full cost for Germany, i.e., 1,110 €/ton, while the variable cost of manufacturing is only $390 €$, with a difference of $720 € /$ ton going directly to its income statement. For Blogisar as a whole, the cost of manufacturing in Germany is $410 €$, and in Tarragona of 
$390 €$, so it is better to manufacture in Germany, but with a difference of only $20 € /$ ton. Then, from this point of view, we may say that there is weak goal congruence.

The problem is, then, in Germany: they 'lose' a $720 €$ contribution because Tarragona is able to manufacture more. Blaming them (and affecting their possible incentives) for that decision is clearly unjust, and it will be so perceived by the German Division. It would seem, then, that there is some problem of goal congruence between the two divisions or between the German Division and the Tarragona Division. But, as we have seen, the Tarragona decision of increasing production 'beyond full capacity' was a good one for the company as a whole: there was weak goal congruence. A centralized planner, if given the choice, would decide to produce in the plant where the costs are lower, i.e., Tarragona. Then, the problem is essentially one of justice: the German Division is formally treated unjustly because in its evaluation there is a big uncontrollable element, like the demand from Tarragona. Often, when this happens, firms have the temptation of changing the structure of the system. For instance, the German Division may argue that it should not be treated as a profit center, but possibly as a cost center, evaluated on standards, budgets, and variance analysis. However, this would make things only worse: the German Division would not have in its evaluation any incentive (tangible or intangible) related with a possible increase in sales, which to some extent should be its priority objective. A 'composite' index weighting, say, cost variances and sales growth is likely to have dysfunctional consequences that were well-known more that a half a century ago (Ridgway 1956), but that seem to have been forgotten today. Measuring profit only for the two divisions as an aggregate and making thereby a unique profit center would clearly be unjust with the Tarragona Division, which is doing just fine, and, thus, would have to be charged the German volume variance.

The structure of the control system is, then, formally unjust, but the alternatives could be much worse. Is there, then, any solution to such a problem?

\section{The sensible solution: informal justice}

A formal solution does not exist in many problems, and the stylized case we have presented here is a clear example. The solution, therefore, can only come through informal systems, and from the informal justice that they can generate. If a strictly formal structure could create goal congruence alone, the process of control and setting specific targets would not be necessary at all. If they are necessary, to a great extent, it is because 
it is important to evaluate the performance of individuals and the responsibility centers as a function of what can be reasonably expected, and this is what is normally reflected in the budget. Then, the 'boss' should evaluate the two divisions, but mainly the German Division in this case, through an elaborate variance analysis of the income statement, including of course the bottom line and many intangible factors. To which the boss should add a personal, informal (and thus subjective) evaluation of to what extent the variances are controllable or uncontrollable by the division. From this, it might follow a tangible or an intangible incentive. Again, it is informal and subjective. Which today it is often considered to be an undesirable property, thereby forgetting that management is by its own nature inevitably subjective.

The informal evaluation, thus, cannot be done with preset formulae, but we can suggest here that, in our case, a good starting point would be to add to the profit of the German division the unexpected deviation in volume created by the Tarragona division. One has to recognize, though, that it may be difficult to determine this with precision. For instance, it will never be obvious to what extent the German division may be partly responsible for the unexpected volume variance. These evaluations are necessarily subjective: quantitative indices fall short when we face a multiplicity of circumstances.

One more point about the general impossibility of formally just control systems. Both internal and external circumstances change through time, and a system that is formally just today may be formally unjust tomorrow and vice-versa. So, stable goal congruence through formal systems may be impossible to achieve. They would have to be changed every so often. In the case we presented, we showed how goal congruence for the Tarragona Division was weak; hence, a relatively small change in the prices of the variable costs may make it become incongruent, although this was very unlikely to happen in the real case. In any case, changing the system every time this happens might be extremely costly. In summary, attempting to fix a goal congruence/justice problem through formal changes in the system may well be impossible; but, if it is not, it may be very impractical.

\section{The invisible variables and informal justice}

Implicitly or explicitly, in situations like the one in our case, some intangible variables are important: not everything ends with monetary incentives, of course. For instance, pride in one's own work: the manager of the German Division will never like showing a 
loss in its accounts, mainly when Tarragona is showing a substantial profit. No matter what the incentive is, and no matter how other variables are evaluated.

In the context of our example, one crucial point is a technical one: the reason why the problem arises is because of an unexpected volume variance, which is a technical accounting issue not entirely easy to understand. The manager of the German Division may not be a well-trained person in accounting matters; and the same may be true for the 'controlor', i.e., line officer in charge of the German Division at the top management level. However, dealing with this situation with informal justice requires a good understanding on both parts of the technical problem that they have. Why is there a problem and how it cannot be formally solved is something both parties have to understand and show each other that they do. If not, the possible informal solution will be only cosmetic or superficial, like "a pat on the back" lacking substantive content.

The controller may have to play a fundamental role. Often, a controller is attributed functions that should not have, like being the person that controls and makes the decision as to what control action is adequate. In contrast, a crucial function of this person is to give technical assistance to both 'controlor' and 'controlee' and to help them understand the situation. The head in the hierarchy must want to understand the relevant issues and the controller must be able to make a sufficient explanation to him. The subordinate who sends the results expect that the person in charge of the division understands in depth what is happening with the numbers, to perceive that there is justice in the treatment received. And this perception, if it is real and not just a impression management issue, is the element needed to re-establish the justice that the formal system alone cannot possible offer in such a complex situations.

Then, of course, the controlor has to make a decision about the controlee's possible rewards, including perhaps a monetary incentive outside the formulae, and/or perhaps a promise of a future incentive whenever some goal is met. It will be the controlor's decision. But basically, she has to have in mind justice.

This proposal goes in the opposite direction of many of the recent developments in this area of research. In recent decades, there has been a trend toward formal systems of incentives based almost exclusively on formal systems based on indicators, under the name of "metrics", "KPI's" and so on, where the concern for justice is completely absent (see, for instance, Kaplan and Norton 1996, a thick book on the subject where the word 'justice' does not ever appear). There is only a concern for 'objectivity' as something absolutely necessary and incentives to push people in the direction that is considered good 
for the firm through some indices that are supposed to reflect strategy. Here we present the opposite point of view: we have shown that justice is important both because it has effects on the future and because is an ethical concept that, but there are situations in which justice can only be effectively introduced informally. Which necessarily implies subjectivity. That is why, we would finally end this analysis using the conceptual model on which we base our case, that is included in the work of Cugueró-Escofet and Rosanas $(2013,2015)$.

\section{Conceptual Analysis}

As mentioned above, this case exemplifies the possibilities offered in a formal model of control systems that incorporates organizational justice. In their article, Cugueró-Escofet and Rosanas (2013) show the existence of four states of goal congruence depending on whether there are the prerequisites of formal and informal justice in the management control system design and use. The authors consider formal justice as those requirements that create justice through the design of a control system and informal justice those requirements that create justice through the use of control systems. The two extreme cases are the maximum goal congruence (where there is formal and informal justice), and the minimum goal congruence (where there is neither formal nor informal justice). These two situations tend to be stable and the case of maximum congruence of objectives typically is a case of excellence, where the managers use control systems consciously and with justice. The goal congruence concept analyzed includes qualitative variables, i.e. there are elements that escape traditional quantitative measures that are typically used to assess whether or not there is goal congruence.

The two most interesting states proposed in their analysis are the perverse and the occasional goal congruence. Perverse goal congruence occurs when the system is designed according to the criteria of formal justice, but the use of the system is unjust. This case is unstable because the managers with their decisions create perceptions of unfairness and therefore this may end up transforming the system into an formally unjust one, and thus goal congruence would go to a minimum goal congruence. The second intermediate case would be that of occasional goal congruence, where the system is formally unjust but the manager uses the system with informal justice. This case is interesting because it illustrates the importance of the managerial action. While the system is used, unjust situations were created and the manager tries to correct the 
consequences informally. At the same time the manager tries to change the system, through managerial action into a more formally just system. Therefore, in the long term this system will end up having a situation of maximum goal congruence of objectives, because it is the normal trend when the formal justice is improved though the just use of the system.

The case we presented in this paper starts with weak quantitative goal congruence, and illustrates the situation quite well. Looking at the four possibilities of goal congruence that were offered in the conceptual model, we could say that the case presented it is a case where formal justice is not possible from the beginning. Given the objectives of the firm as a whole and the objectives of the two divisions, a maximum goal congruence of a quantitative character cannot be achieved. However, it can be developed by applying informal justice of a qualitative nature into the evaluation; which will be helpful in achieving the key-variables of the German division. Whenever this happens, specifically, it is when sales achieve a level that is high enough. Then the volume variance and the internal sales will lose importance and the structure of the control system will be just, having then the possibility of reaching maximum goal congruence if management acts with informal justice.

In addition, the situation presented in the case may illustrate a situation that is particularly interesting in applying the model of Cugueró-Escofet and Rosanas. Will the situation of maximum goal congruence, if it is reached, be stable? In theory, if circumstances do not change, yes; but if there is a change either in the environment (for instance, in the key variables) or within the firm (a change of strategy or structure), the new situation may again be formally unjust. Maximum goal congruence may thus not be stable because it cannot incorporate all the possibilities for the future. Inevitably, the formal system may end up generating injustices. Inevitably, therefore, the maximum goal congruence will be qualitative, and always through the occasional goal congruence, when the manager is aware that it is not possible to achieve maximum goal congruence only based on quantitative variables, and so she is informally just. In this sense, we suggest that this is a limitation of this model that still makes more evident the need for informal justice: not just to reach stable maximum goal congruence, but to compensate for a situation where stable formal justice is not possible, and it makes more necessary an intense managerial action. In any case, the stability of a maximum goal congruence situation under internal or external changes remains open to question and suggests further research on the matter. 


\section{Conclusions}

This paper has attempted to show how, even though there are situations where it is impossible to design a formally just management control system, informal justice may be a sufficient condition for the management control problem to have a solution. For this purpose, we have presented a stylized situation, based in a composite of real-world cases, where it is clear that a design of a formal control system that promotes the achievement of the key economic variables of the firm and is formally just at the same time it is not possible. Then, if we focus the system on the achievement of the key economic variables, and therefore is formally unjust, the solution to the problem on injustice should come from the informal system. Using the system in a way that is informally just will lead to two types of (complementary) outcomes. First, in the short-run, we can obtain a situation that is just, and because of that reason can be perceived as fair by the employees evaluated by the system (in the terminology of Cugueró-Escofet \& Rosanas, there is occasional goal congruence), with the positive consequences in terms of morale and employee identification that we often associate with justice. This conclusion can be generalized independently of the key variables present in the case, because this is a result of CugueróEscofet and Rosanas' model. Second, in the long-run, when the objectives in terms of the key variables start being met, the formal control system that was unjust will become less and less so: whenever the German Division reaches capacity (or gets close to it), the system will not be formally unjust anymore. This conclusion may not be so easily generalizable in all the cases, because it would depend on the key variables present in every specific situation. Therefore, according to Cugueró-Escofet and Rosanas (2013, 2015), in a formally just system governed with informal justice at the same time, the organization will then achieve maximum goal congruence, which should be a stable situation. Of course, this does not mean that it will remain in that state forever: there may be many reasons (internal or external) why this might change, and the organization should be able to respond to them adequately. A detailed examination of why this might happen, and how the organization should be able to respond, unfortunately exceeds the objectives of this paper, and thus becomes a possible line of further research. We believe that these conclusions are far-reaching. All human beings want to work in an environment that is just (or, to be more precisely, that is perceived ad "fair"), but the literature on management control systems typically ignores justice as a property of the system. Beyond the general idea that the systems should be just, we have illustrated how this can be done in practice, following the analysis of Cugueró-Escofet and Rosanas $(2013,2015)$. We hope that our 
contribution can influence both academicians and practitioners to take justice and fairness into account. This would at the same time improve the results of the firm and satisfy the motives of the members of the organization, which according to one of the Management Classics, Chester Barnard (1938) is one of the crucial variables for organizational survival in the long run. 


\section{REFERENCES}

Anthony, R. N. (1988). The Management Control Function. Boston, Massachussets: The Harvard Business School Press.

Anthony, R. N. \& Govindarajan, V. (2003). Management Control Systems, 11th Edition. Homewood, Illionois: Richard D. Irwin.

Aristotle (2000). 'Nicomachean Ethics.' The Internet Classics Archive by Daniel C. Stevenson.

Barnard, C. I. (1938). The functions of the executive. Boston: Harvard University Press.

Coletti, A. L., Sedatole, K. L. \& Towry, K. L. (2005). 'The Effect of Control Systems on Trust and Cooperation in Collaborative Environments.' Accounting Review: 477-500. American Accounting Association.

Cropanzano, R. \& Goldman, B. M. (2014). "'Justice" and "Fairness" are not the same thing.' Journal of Organizational Behavior, 36:2, 313-18.

Cugueró-Escofet, N. \& Fortin, M. (2013). 'One Justice or Two? A Model of Reconciliation of Normative Justice Theories and Empirical Research on Organizational Justice.' Journal of Business Ethics, DOI 10.1007/s10551-013-1881-1.

Cugueró-Escofet, N. \& Rosanas, J. M. (2013). 'The just design and use of Management Control Systems as requirements for Goal Congruence.' Management Accounting Research, 24:1, 23-40.

Cugueró-Escofet, N. \& Rosanas, J. M. (2015). 'Social dynamics of Justice: The Ex-ante and Ex-post Justice Interplay with Formal and Informal Elements of Management Control Systems.' In D. D. S. Stephen W. Gilliland, Daniel P. Skarlicki (Ed.) Social dynamics of organizational justice. Charlotte, NC: Information Age Publishing.

Eccles, R. G. (1983). 'Control with Fairness in Transfer Pricing.' Harvard Business Review, 72:6, 146-61

Eccles, R. G. (1985). The transfer pricing problem : a theory for practice. Lexington, Massachussets: Lexington Books.

Hartmann, F. \& Slapnicar, S. (2009). 'How formal performance evaluation affects trust between superior and subordinate managers.' Accounting, Organizations and Society, 34:6-7, 722-37.

Kaplan, R. \& Norton, D. (1996). The Balanced Scorecard: Translating Strategy into Action. Boston Ma: Harvard Business School Press.

Langevin, P. \& Mendoza, C. (2013). 'How can management control system fairness reduce manager's unethical behaviors?' European Management Journal, 31, 209-22. 
Merchant, K. A. \& Van der Stede, W. (2007). Management Control Systems: Performance Measurement, Evaluation and Incentives. Prentice Hall.

Plato (2006). The Republic. New Haven: Yale University Press.

Polanyi, M. (1974). Personal Knowledge: Towards a Post-Critical Philosophy. Chicago, Ill: University of Chicago Press.

Ridgway, V. F. (1956). 'Dysfunctional consequences of performance measurements.' Administrative Science Quarterly, 1:3, 240-47.

Rosanas, J. M. (2008). 'Beyond Economic Criteria: A Humanistic Approach to Organizational Survival.' Journal of Business Ethics, 78, 447-62.

Rosanas, J. M. (2013). Decision-Making in an Organizational Context. Beyond Economic Criteria. Houndsmills, Basingstoke, Hampshire: Palgrave Macmillan.

Simons, R. (1999). Performance measurement and control systems for implementing strategy. Text an cases. Englewood Cliffs, NJ: Prentice-Hall.

Thompson, J. (1967). Organizations in Action: Social Science Bases of Administrative Theory. New York: McGraw-Hill.

Vancil, R. F. (1973). 'What kind of management control do you need?' Harvard Business Review. 